\title{
Inhibition of rapamycin-induced Akt phosphorylation by cotylenin A correlates with their synergistic growth inhibition of cancer cells
}

\author{
TAKASHI KASUKABE ${ }^{1}$, JUNKO OKABE-KADO ${ }^{1}$, YU HARANOSONO $^{2}$, NOBUO KATO $^{2}$ and YOSHIO HONMA ${ }^{3}$ \\ ${ }^{1}$ Research Institute for Clinical Oncology, Saitama Cancer Center, Saitama 362-0806; \\ ${ }^{2}$ Institute of Scientific and Industrial Research, Osaka University, Osaka 567-0047; \\ ${ }^{3}$ School of Medicine, Shimane University, Izumo 693-8501, Japan
}

Received October 4, 2012; Accepted November 23, 2012

DOI: $10.3892 /$ ijo.2012.1745

\begin{abstract}
Cotylenin A, a plant growth regulator, and rapamycin, an inhibitor of the mammalian target of rapamycin, are potent inducers of differentiation in myeloid leukemia cells and also synergistically inhibit the proliferation of several human breast cancer cell lines including MCF-7 in vitro and in vivo. However, the mechanisms of the combined effects of cotylenin A and rapamycin are still unknown. Activated Akt induced by rapamycin has been suggested to attenuate the growth-inhibitory effects of rapamycin, serving as a negative feedback mechanism. In this study, we found that cotylenin A could suppress rapamycin-induced phosphorylation of Akt (Ser473) in MCF-7 cells and lung carcinoma A549 cells and that cotylenin A also enhanced the rapamycin-induced growth inhibition of MCF-7 and A549 cells. ISIR-005 (a synthetic cotylenin A-derivative) was able to enhance rapamycin-induced growth inhibition and could also markedly inhibit rapamycininduced phosphorylation of Akt. We also found that the HSP90 inhibitor 17-allylamino-17-demethoxygeldanamycin (17-AAG) or arsenic trioxide (ATO) in combination with rapamycin markedly inhibited the growth of MCF-7 cells and 17-AAG or ATO suppressed rapamycin-induced phosphorylation of Akt. The PI3K inhibitor LY294002 also suppressed rapamycin-induced phosphorylation of Akt and combined treatment showed synergistic growth inhibition of MCF-7 cells. Rapamycin inhibited growth more significantly in Akt siRNA-transfected MCF-7 cells than in control siRNA-transfected MCF-7 cells. These results suggest that the inhibition of rapamycin-induced Akt phosphorylation by cotylenin A correlates with their effective growth inhibition of cancer cells.
\end{abstract}

Correspondence to: Dr Takashi Kasukabe, Research Institute for Clinical Oncology, Saitama Cancer Center, 818 Komuro, Ina-machi, Saitama 362-0806, Japan

E-mail: kasukabe@cancer-c.pref.saitama.jp

Key words: cotylenin A, rapamycin, Akt, growth inhibition, breast cancer cells

\section{Introduction}

Breast cancer remains one of the leading causes of cancerrelated death worldwide. Although chemotherapy has improved outcomes for patients, the marginal benefits achieved with cytotoxic agents seem to have reached a plateau (1). Recently, preventive agents and targeted therapies directed at the estrogen receptor, progesterone receptor, and human epidermal growth factor 2 receptor have resulted in improved clinical outcomes for many women with breast cancer (2). However, further challenges remain in treating tumors that do not express these molecular targets or tumor cells that become resistant for these molecular targets. Hence, the development of new therapeutic agents for these clinically intractable tumors is highly desirable.

The mammalian target of rapamycin (mTOR), a serine/threonine kinase, integrates multiple signaling pathways, including cell growth and survival (3). Activation of phosphatidylinositol 3-kinase (PI3K)/Akt/mTOR signaling contributes to the pathogenesis of many tumor types including breast cancer (4-6). Two distinct mTOR complexes, mTORC1 and mTORC2, have been identified and have differential sensitivity to rapamycin (Rapa). mTORC1 is downstream of Akt, sensitive to Rapa inhibition, and controls cap-dependent protein translation (6). One of the best-studied mTOR substrates is p70 ribosomal S6 kinase (p70S6K). In contrast, mTORC2 is directly upstream of Akt and is resistant to Rapa. Akt can be activated by phosphorylation at two different sites, S473 by mTORC2 and T308 by phosphoinositide-dependent kinase 1 (PDK1). Constitutive activation of the PI3K/Akt/mTOR signaling axis leads to uncontrolled tumor cell proliferation and survival (4,7). Rapa is an allosteric inhibitor of mTOR. Rapa analogues (rapalogs) have been approved for the treatment of neuroendocrine tumors, renal cell carcinoma, and subependymal giant cell astrocytoma associated with tuberous sclerosis, and have very promising clinical benefits in other tumor types such as breast and endometrial cancer. However, single agent rapalogs have only achieved modest antitumor activity in a clinical setting (8). The limited anticancer efficacy of rapalogs can be explained by two possible mechanisms. First, rapalogs have been shown to induce Akt activation. Insulin-like growth factor-I (IGF-I) and 

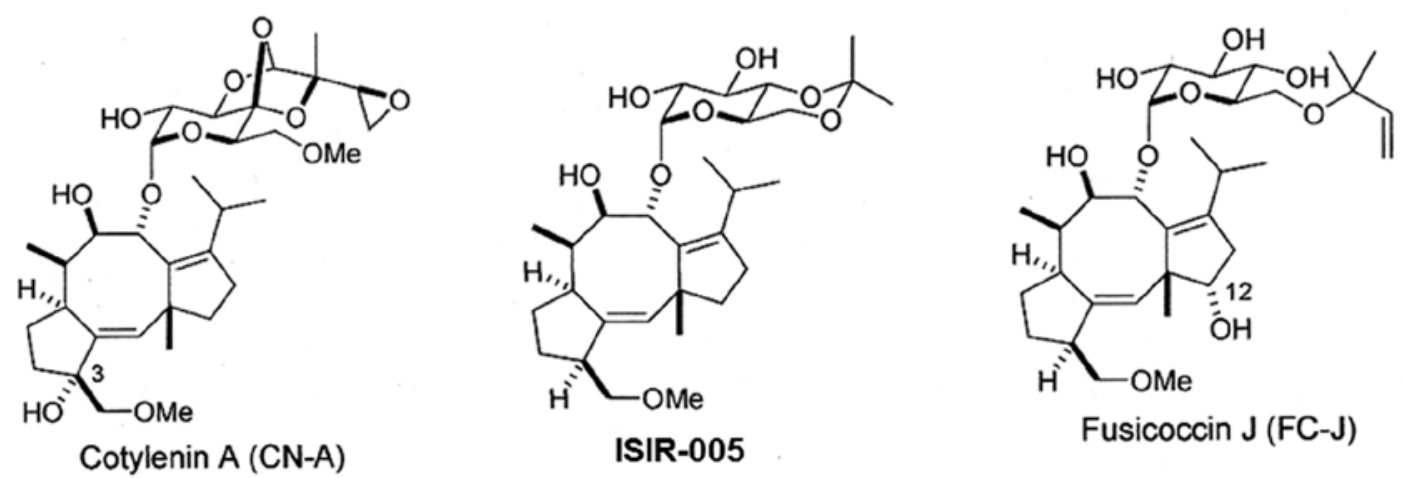

Figure 1. Structures of cotylenin A (CN-A) and CN-A analogues.

insulin-dependent induction of the PI3K/Akt pathway leads to feedback inhibition of signaling due to mTOR/S6K-mediated phosphorylation and degradation of IRS-1. Rapa-induced Akt activation has been primarily attributed to the loss of this negative feedback loop. This feedback loop activation of Akt was not only in vitro but was also observed in a phase I clinical trial of the Rapa analog everolimus $(7,8)$. Second, rapalogs incompletely block mTORC1 downstream signaling $(9,10)$.

We have examined whether inducers of differentiation in leukemia cells can control the growth of solid tumors. Cotylenin A (CN-A), which is a fucicoccan-diterpene glycoside with a complex sugar moiety, was originally isolated as a plant growth regulator and has been shown to affect several physiological processes in higher plants (11). We previously reported that $\mathrm{CN}-\mathrm{A}$ has a potent differentiation-inducing activity in several human and murine myeloid leukemia cell lines and in leukemia cells that were freshly isolated from patients with acute myeloid leukemia (12-15). We previously found that treatment with CN-A plus Rapa, which also has a potent differentiation-inducing activity in myeloid leukemia cells (16), effectively inhibited the proliferation of human breast cancer cell line MCF-7 cells in vitro and in vivo (17). In the present study we found that $\mathrm{CN}-\mathrm{A}$ inhibited Rapa-induced phosphorylation of Akt (Ser473). Our results suggest that the inhibition of Rapa-induced Akt phosphorylation by $\mathrm{CN}-\mathrm{A}$ correlates with their effective growth inhibition of cancer cells.

\section{Materials and methods}

Cell culture. Human breast cancer cell line MCF-7 cells, adriamycin-resistant MCF-7/Adr cells, and human lung cancer A549 cells were cultured in RPMI-1640 supplemented with $10 \%$ fetal bovine serum at $37^{\circ} \mathrm{C}$ in a humidified atmosphere of $5 \%$ carbon dioxide in air.

Materials. Rapamycin, arsenic trioxide and LY294002 were purchased from Sigma-Aldrich (St. Louis, MO, USA). 17-Allylamino-17-demethoxygeldanamycin (17-AAG) was obtained from LC Laboratories (Woburn, MA, USA). CN-A, ISIR-005 and fusicoccin J (FC-J) were prepared as described previously $(11,18)$. The structures of CN-A, ISIR-005 and
FC-J were shown in Fig. 1. Anti-phospho-Akt (Ser473), anti-Akt and anti-phospho-p70 S6 kinase (Thr389) antibodies were purchased from Cell Signaling Technology (Danvers, MA, USA). Anti- $\alpha$-tubulin antibody, Akt1/2 siRNA and control siRNA were obtained from Santa Cruz Biotechnology (Santa Cruz, CA, USA).

Assay of cell growth. Cells were seeded at $1-3 \times 10^{4}$ cells $/ \mathrm{ml}$ in a 24-well multidish. After culture with or without test compounds for the indicated times, viable cells were examined by a modified MTT (3-(4,5-dimethylthiazol-2yl)-2,5-diphenyltetrazolium bromide) assay (17).

Western blot analysis. Cells were packed after washing with cold PBS and then lysed at a concentration of $1 \times 10^{7}$ cells $/ \mathrm{ml}$ in lysis buffer CelLytic ${ }^{\mathrm{TM}}-\mathrm{M}$ (Sigma-Aldrich Inc.) supplemented with a proteinase inhibitor cocktail and phosphatase inhibitor cocktail 1/2 (Sigma-Aldrich Inc.). Equal amounts of protein were separated on 10-20\% SDS-polyacrylamide gels (Wako, Osaka, Japan). Proteins were electrophoresed on gels and transferred to an Immobilon-P membrane (Millipore, Bedford, MA, USA) using the following antibodies: rabbit anti-phospho-Akt (Ser473) antibody (1:1,000), rabbit anti-Akt antibody $(1: 1,000)$, rabbit anti-phospho-p70 S6 kinase (Thr389) antibody $(1: 1,000)$ or mouse anti- $\alpha$-tubulin antibody (1:5,000). An anti-rabbit or anti-mouse IgG HRP-linked antibody (Cell Signaling Technology, was used as a secondary antibody (1:2,000 dilution). Bands were identified by treatment with Immune-Star ${ }^{\mathrm{TM}}$ HRP chemiluminescence (Bio-Rad Laboratories, Hercules, CA, USA) for $5 \mathrm{~min}$ at room temperature and detected using a FujiLumino Image Analyser LAS-4000 system (Fuji Film Co. Ltd, Tokyo, Japan) (19). All western blots shown are representative of at least 3 independent experiments.

siRNA transfection. A total of $0.75 \times 10^{4}$ cells were seeded into the 24-well multidish and transfected with siRNA (20 nM) by siLentFect ${ }^{\mathrm{TM}}$ Lipid Reagent (Bio-Rad Laboratories). The next day, Rapa was added to cells and cultured for a further 4 days. Viable cells were then examined by the MTT assay. To determine the knockdown efficiency, western blot analysis was done using cell lysates from siAkt- or control siRNA-transfected cells. 
A

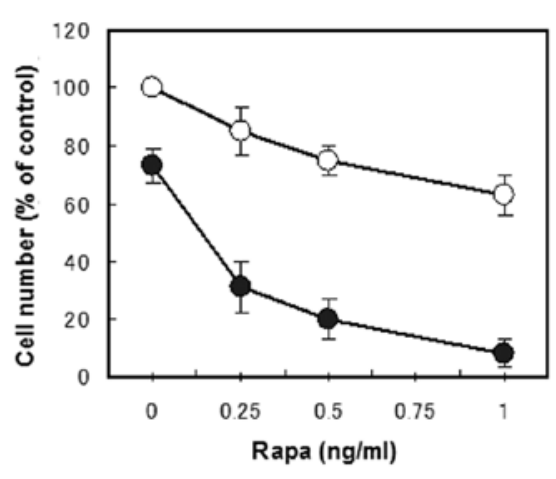

C

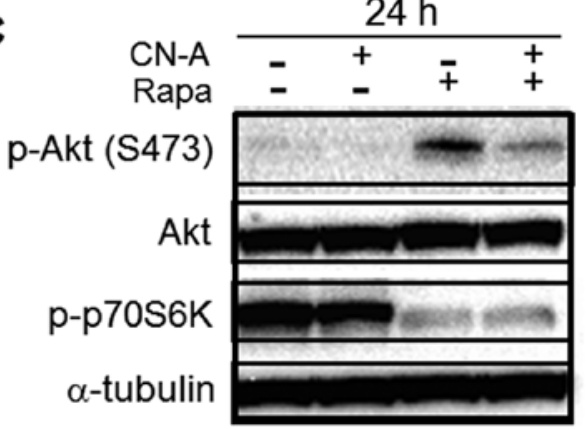

B

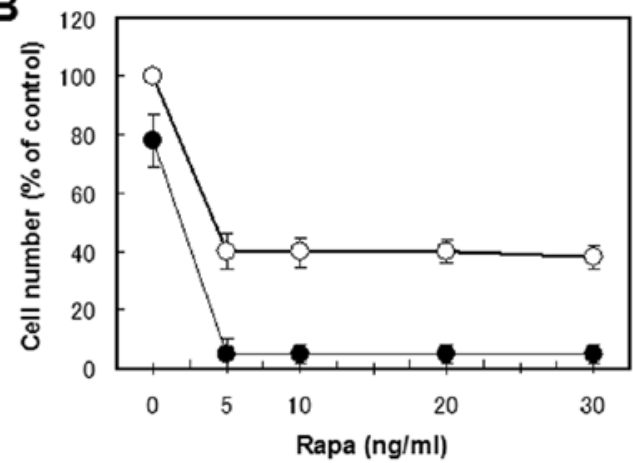

D

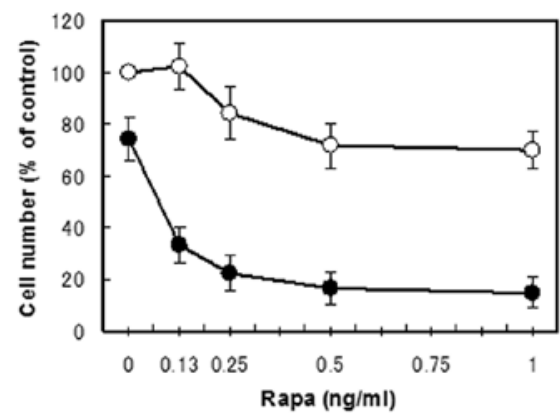

Figure 2. Cotylenin A (CN-A) enhances rapamycin (Rapa) induced growth inhibition and inhibits Rapa-induced phosphorylation of Akt in MCF-7 cells. (A and B) MCF-7 cells or (D) MCF-7/Adr (1x10 cells $/ \mathrm{ml})$ were cultured with Rapa in the presence $(\bullet)$ and absence (O) of $5 \mu \mathrm{g} / \mathrm{ml} \mathrm{CN}-\mathrm{A}$ for 5 days. Then, cell numbers were determined by the MTT assay. Values are expressed as mean \pm standard deviation of three determinations. (C) Phosphorylation of Akt (p-Akt S473) and p70S6K (p-p70S6K) after treatment with $0.5 \mathrm{ng} / \mathrm{ml}$ Rapa in the presence or absence of $5 \mu \mathrm{g} / \mathrm{ml} \mathrm{CN}$-A for $24 \mathrm{~h}$ in MCF-7 cells was determined by western blot analysis. Expression of $\alpha$-tubulin protein served as the loading control. Similar results were obtained in two additional experiments.

\section{Results}

The suppression of Rapa-induced phosphorylation of Akt (Ser473) by CN-A correlates with their synergistic growth inhibition of MCF-7 cells. As described in our previous reports (17,19), CN-A and Rapa synergistically inhibited the proliferation of human breast cancer MCF-7 cells (Fig. 2A and B). Although lower doses (0.25-5 ng/ml) of Rapa alone inhibited the growth of MCF-7 cells dose-dependently to around $40 \%$ of controls, additional higher doses $(10-30 \mathrm{ng} / \mathrm{ml})$ of Rapa did not decrease cell numbers further (Fig. 2B). As previously reported $(20,21)$, the inhibition of mTOR signaling by Rapa led to an increase in Akt phosphorylation on Ser473 (Fig. 2C) in MCF-7 cells. Therefore, these blunt effects of Rapa on the growth of MCF-7 cells may be due to the negative feedback activation of Akt signaling. We found that CN-A $(5 \mu \mathrm{g} / \mathrm{ml})$ was able to suppress Rapa-induced phosphorylation of Akt on Ser473 (Fig. 2C). Although CN-A (5 $\mu \mathrm{g} / \mathrm{ml})$ alone slightly inhibited the proliferation of MCF-7 cells, Rapa at $1-30 \mathrm{ng} / \mathrm{ml}$ almost completely suppressed the growth of MCF-7 cells in the presence of CN-A (Fig. 2A and B). Similar results were obtained using adriamycin-resistant MCF-7 cells (Fig 2D). Rapa induced phosphorylation of Akt on Ser 473 from $1 \mathrm{~h}$ after treatment and maintained higher levels of phosphorylation of Akt until at least $48 \mathrm{~h}$ after treatment, although Rapa clearly inhibited phosphorylation of p70 S6K on Thr389 from $1 \mathrm{~h}$ after treatment (Fig. 3). CN-A significantly inhibited Rapa-induced phosphorylation of Akt on Ser473 from 3-48 h after treatment,

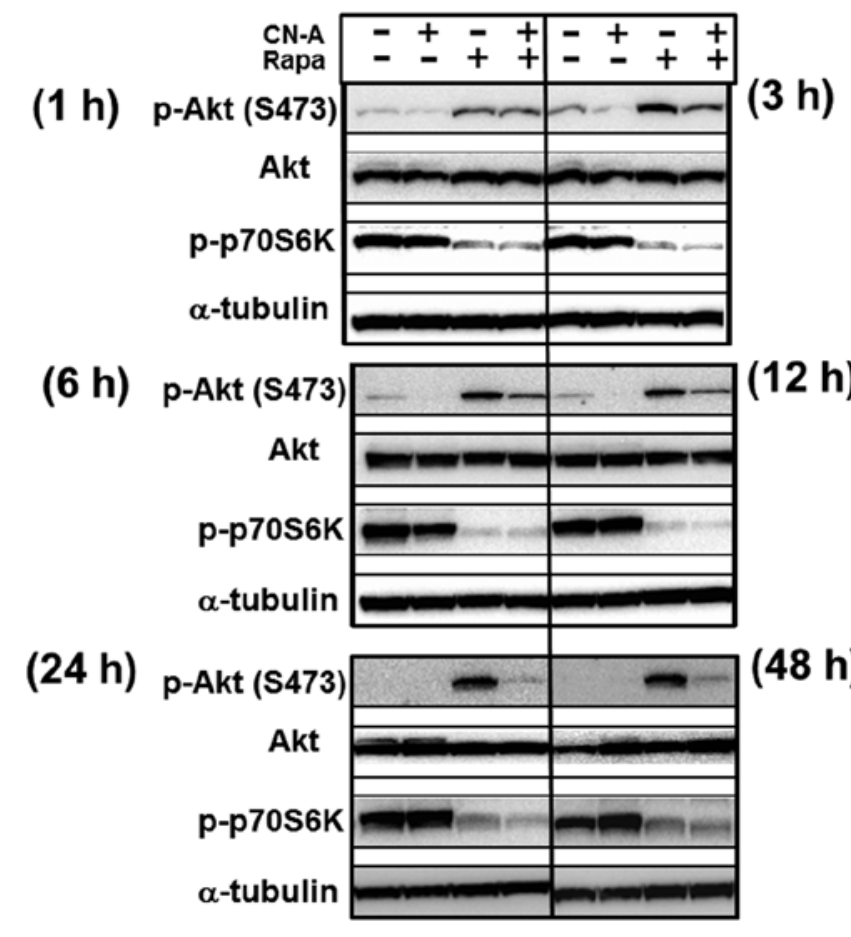

Figure 3. Effect of CN-A on Rapa-induced phosphorylation of Akt in MCF-7 cells. Phosphorylation of Akt (p-Akt S473) and p70S6K (p-p70S6K) after treatment with $0.5 \mathrm{ng} / \mathrm{ml}$ Rapa in the presence or absence of $5 \mu \mathrm{g} / \mathrm{ml} \mathrm{CN}$-A for $1,3,6,12,24$ or $48 \mathrm{~h}$ in MCF-7 cells was determined by western blot analysis. Expression of $\alpha$-tubulin protein served as the loading control. Similar results were obtained in two additional experiments. 
A

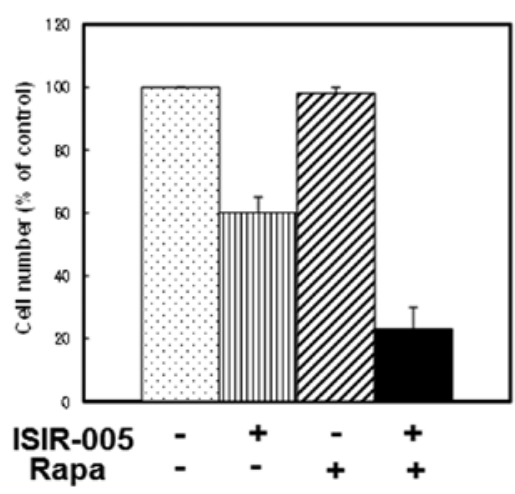

B

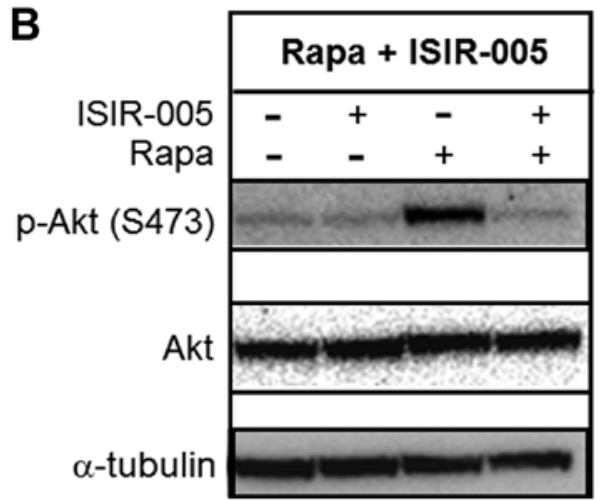

C

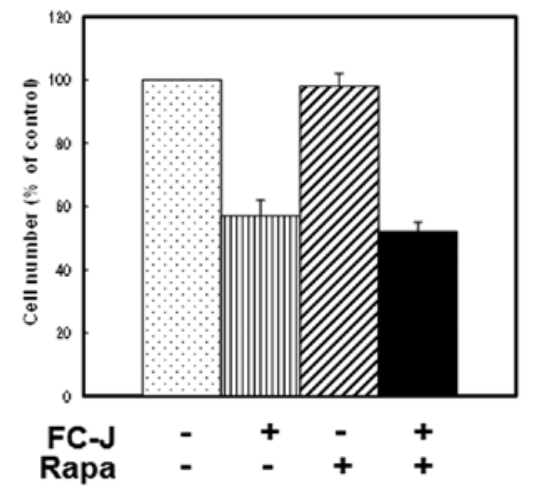

D

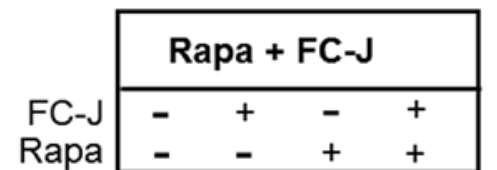

p-Akt (S473)

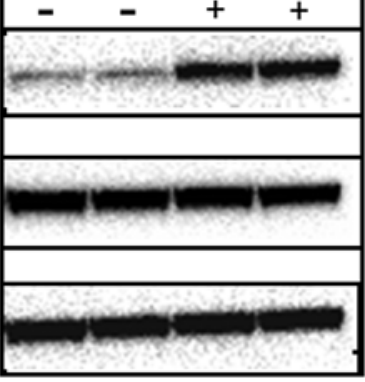

Figure 4. Effects of CN-A analogues on the growth of MCF-7 in the presence of Rapa and Rapa-induced phosphorylation of Akt in MCF-7 cells. (A and C) MCF-7 cells $\left(1 \times 10^{4}\right.$ cells $\left./ \mathrm{ml}\right)$ were cultured with $0.5 \mathrm{ng} / \mathrm{ml}$ Rapa in the presence or absence of (A) $4 \mu \mathrm{g} / \mathrm{ml}$ ISIR-005 or (C) $3 \mu \mathrm{g} / \mathrm{ml}$ FC-J for $5 \mathrm{days}$. Then, cell numbers were determined by the MTT assay. Values are expressed as mean \pm standard deviation of three determinations. (B and D) Phosphorylation of Akt (p-Akt S473) after treatment with $0.5 \mathrm{ng} / \mathrm{ml}$ Rapa in the presence or absence of (B) $4 \mu \mathrm{g} / \mathrm{ml}$ ISIR-005 or (D) $3 \mu \mathrm{g} / \mathrm{ml}$ FC-J for $24 \mathrm{~h}$ in MCF-7 cells was determined by western blot analysis. Expression of $\alpha$-tubulin protein serves as the loading control. Similar results were obtained in two additional experiments.

although CN-A did not significantly affect the Rapa-induced inhibition of phosphorylation of p70 S6K on Thr389 (Fig. 3).

Effects of $\mathrm{CN}-\mathrm{A}$ analogues on the growth and phosphorylation of Akt (Ser473) in the presence of Rapa. We next examined whether the active $\mathrm{CN}-\mathrm{A}$ analogue and Rapa also cooperatively inhibited the growth of MCF-7 cells and whether the active $\mathrm{CN}-\mathrm{A}$ analogue could suppress Rapa-induced phosphorylation of Akt. Although ISIR-005, a synthetic CN-A-derivative, at $4 \mu \mathrm{g} / \mathrm{ml}$ inhibited the growth of MCF-7 cells to $60 \%$ of controls after the 5-day treatment and Rapa at $0.5 \mathrm{ng} / \mathrm{ml}$ slightly inhibited the growth of MCF-7 cells, combined treatment of ISIR-005 plus Rapa inhibited growth to $23 \%$ of controls (Fig. 4A). This combined treatment of ISIR-005 plus Rapa also clearly inhibited Rapa-induced phosphorylation of Akt on Ser473 (Fig. 4B). On the contrary, FC-J, a CN-A-related natural product, at $3 \mu \mathrm{g} / \mathrm{ml}$ also inhibited the growth of MCF-7 cells to $57 \%$ of controls after the 5-day treatment (Fig. 4C), but did not enhance Rapa-induced growth inhibition (Fig. 4C) and also could not inhibit Rapa-induced phosphorylation of Akt (Fig. 4D). Furthermore, similar results were obtained from Rapa treatment plus another inactive analogue of CN-A (data not shown).

$C N-A$ suppresses Rapa-induced phosphorylation of Akt and enhances Rapa-induced growth inhibition of lung cancer A549 cells. We next examined whether CN-A could inhibit Rapa-induced phosphorylation of Akt and exert synergistic growth inhibition of cells other than MCF-7 cells when $\mathrm{CN}-\mathrm{A}$ plus Rapa were used as the treatment. As we reported previously (17), the sensitivity of human non-small cell lung carcinoma A549 cells to Rapa was also markedly affected by CN-A (Fig. 5A). The synergistic growth inhibitory effects of Rapa and CN-A were also accompanied by the suppression of Rapa-induced phosphorylation of Akt (Ser473) by CN-A in A549 cells (Fig. 5B). These findings indicate that the correlation between the suppression of Rapa-induced phosphorylation of Akt (Ser473) by CN-A and their synergistic growth inhibition was not restricted to MCF-7 cells.

Drugs that inhibit Rapa-induced phosphorylation of Akt (Ser473) can also enhance Rapa-induced growth inhibition of MCF-7 cells. We examined whether substances that could inhibit Rapa-induced phosphorylation of Akt (Ser473) other than CN-A or the CN-A analogue ISIR-005 could enhance Rapa-induced growth inhibition of MCF-7 cells. As it was previously reported (22-24) that the HSP90 inhibitor 17-AAG inhibited phosphorylation of Akt (Ser473) in several solid tumor cells including MCF-7 cells, we examined the effects of 17-AAG on Rapa-induced phosphorylation of Akt (Ser473) and Rapa-induced growth inhibition of MCF-7 cells. As shown in Fig. 6B, 17-AAG clearly suppressed Rapa-induced phosphorylation of Akt. Although 17-AAG (30 nM) or Rapa $(0.5 \mathrm{ng} / \mathrm{ml})$ alone inhibited cell growth to about 51 or $41 \%$ of controls, respectively, combined treatment with 17-AAG and 
A

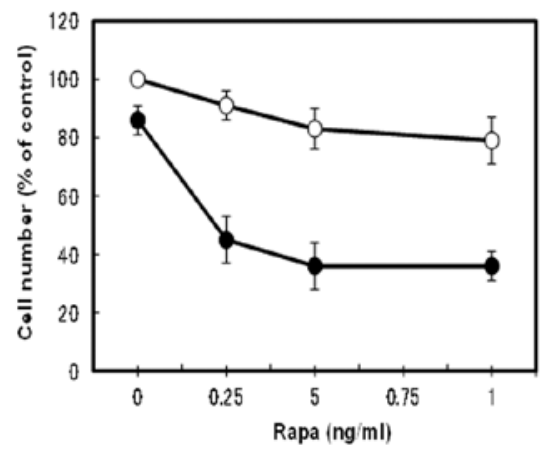

B

$\mathrm{CN}-\mathrm{A}(20 \mu \mathrm{g} / \mathrm{ml})$

Rapa (1 ng/ml)

p-Akt (S473)

Akt

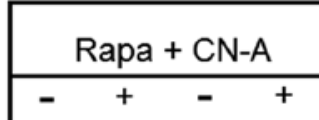

- $\quad+\quad+$

p-p70s6K

$\alpha$-tubulin
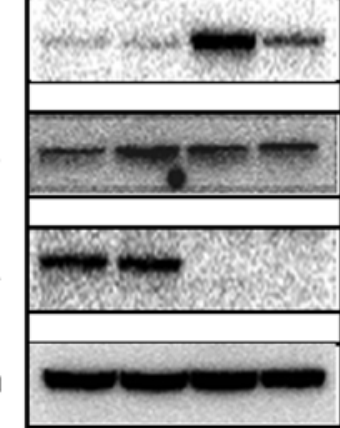

Figure 5. CN-A enhances Rapa-induced growth inhibition and inhibits Rapa-induced phosphorylation of Akt in A549 cells. (A) A549 cells (1x10 cells/ml) were cultured with Rapa in the presence (•) or absence (O) of $20 \mu \mathrm{g} / \mathrm{ml} \mathrm{CN-A}$ for 5 days. Then, cell numbers were determined by the MTT assay. Values are expressed as mean \pm standard deviation of three determinations. (B) Phosphorylation of Akt (p-Akt S473) and p70S6K (p-p70S6K) after treatment with $1 \mathrm{ng} / \mathrm{ml}$ Rapa in the presence or absence of $20 \mu \mathrm{g} / \mathrm{ml} \mathrm{CN}-\mathrm{A}$ for $24 \mathrm{~h}$ in A549 cells was determined by western blot analysis. Expression of $\alpha$-tubulin protein serves as the loading control. Similar results were obtained in two additional experiments.

A

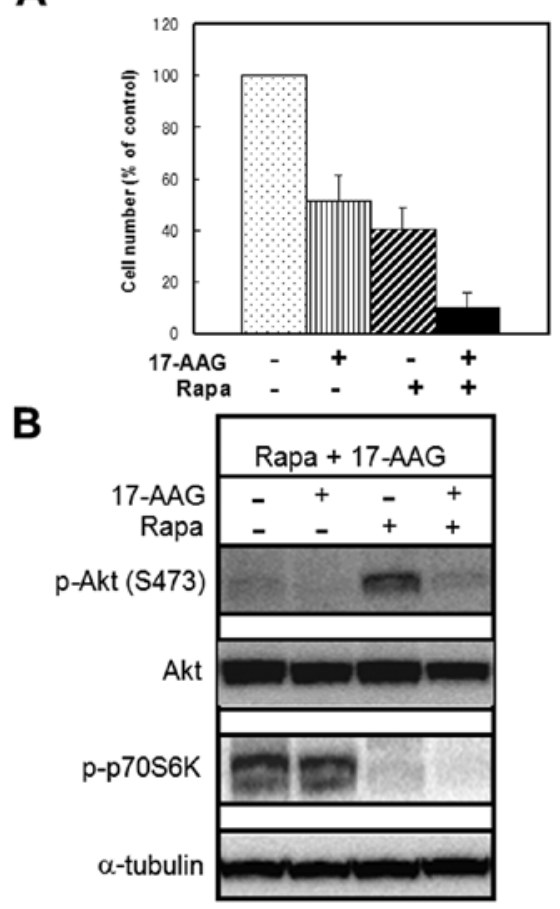

C

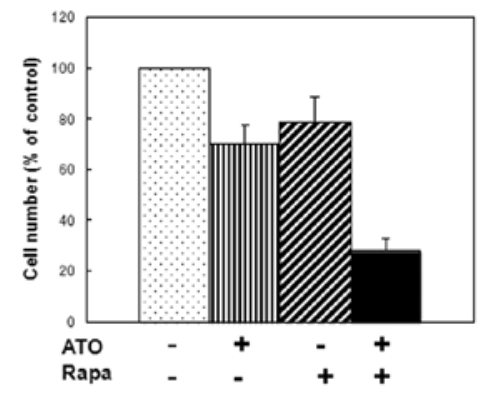

D

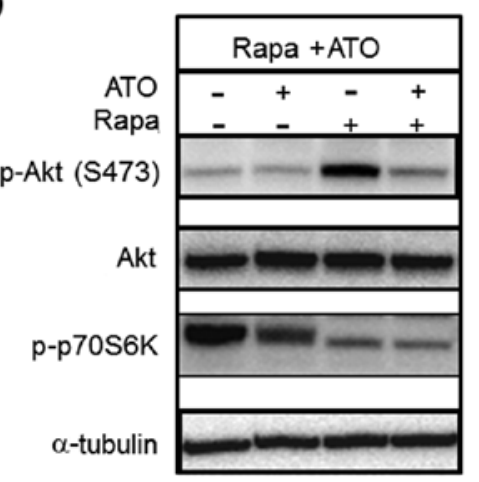

Figure 6. Effect of 17-allylamino-17-demethoxygeldanamycin (17-AAG) or arsenic trioxide (ATO) on the growth of MCF-7 cells in the presence of Rapa and Rapainduced phosphorylation of Akt in MCF-7 cells. (A and C) MCF-7 cells (1x104 cells $/ \mathrm{ml}$ ) were cultured with (A) $0.5 \mathrm{ng} / \mathrm{ml}$ or (C) $0.2 \mathrm{ng} / \mathrm{ml} \mathrm{Rapa}$ in the presence and absence of (A) $30 \mathrm{nM}$ 17-AAG or (C) $4 \mu \mathrm{M}$ ATO for 5 days. Then, cell numbers were determined by the MTT assay. Bars show the mean \pm standard deviation of three determinations. (B) Phosphorylation of Akt (p-Akt S473) and p70S6K (p-p70S6K) after treatment with $0.5 \mathrm{ng} / \mathrm{ml}$ Rapa in the presence or absence of $30 \mathrm{nM}$ 17-AAG for $24 \mathrm{~h}$ in MCF-7 cells was determined by western blot analysis. (D) Phosphorylation of Akt (p-Akt S473) and p70S6K (p-p70S6K) after treatment with $0.2 \mathrm{ng} / \mathrm{ml}$ Rapa in the presence or absence of $4 \mu \mathrm{M}$ ATO for $24 \mathrm{~h}$ in MCF-7 cells was determined by western blot analysis. Expression of $\alpha$-tubulin protein serves as the loading control. Similar results were obtained in two additional experiments.

Rapa inhibited cell growth to $10 \%$ of controls (Fig. 6A). Arsenic trioxide (ATO) is also known to inhibit phosphorylation of Akt in several solid tumor cells (25-27). Therefore, we examined the effect of ATO on Rapa-induced phosphorylation of Akt (Ser473) and Rapa-induced growth inhibition of MCF-7 cells. ATO also suppressed Rapa-induced phosphorylation of Akt in MCF-7 cells (Fig. 6D). Although ATO $(4 \mu \mathrm{M})$ or Rapa $(0.2 \mathrm{ng} / \mathrm{ml})$ alone inhibited cell growth to 70 or $79 \%$ of controls, combined 
A

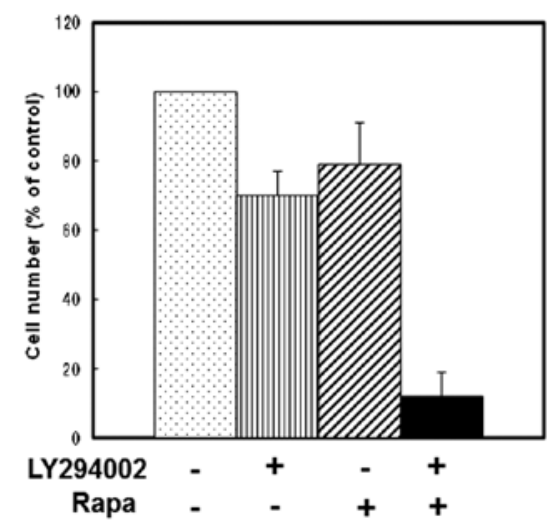

B

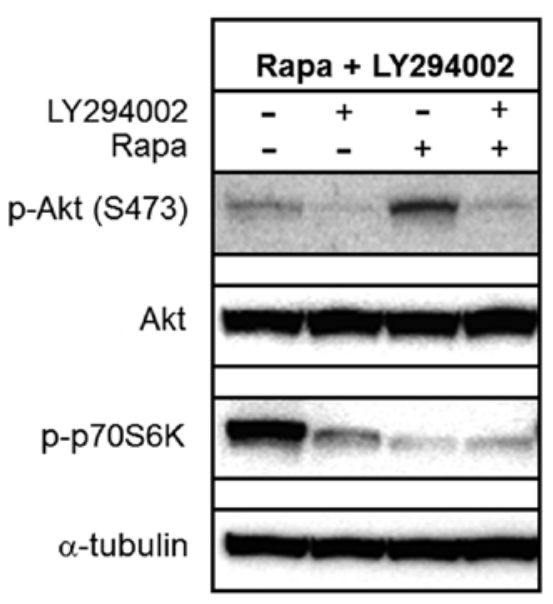

Figure 7. Effect of LY294002 on the growth of MCF-7 cells in the presence of Rapa and Rapa-induced phosphorylation of Akt in MCF-7 cells. (A) MCF-7 cells $\left(1 \times 10^{4}\right.$ cells $\left./ \mathrm{ml}\right)$ were cultured with $0.2 \mathrm{ng} / \mathrm{ml}$ Rapa in the presence or absence of $3 \mu \mathrm{M} \mathrm{LY} 294002$ for 5 days. Then, cell numbers were determined by the MTT assay. Values are expressed as mean \pm standard deviation of three determinations. (B) Phosphorylation of Akt (p-Akt S473) and p70S6K (p-p70S6K) after treatment with $0.2 \mathrm{ng} / \mathrm{ml}$ Rapa in the presence or absence of $3 \mu \mathrm{M} \mathrm{LY} 294002$ for $24 \mathrm{~h}$ in MCF-7 cells was determined by western blot analysis. Expression of $\alpha$-tubulin protein serves as the loading control. Similar results were obtained in two additional experiments.

A

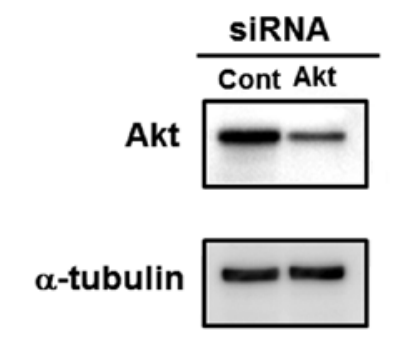

B

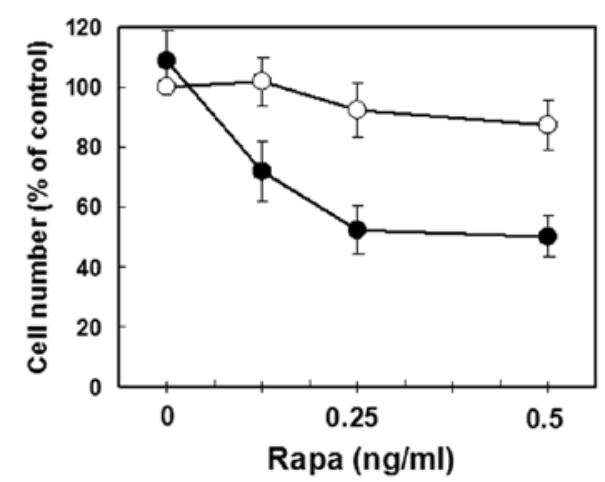

Figure 8. Akt knockdown induced by Akt small interfering RNA (siRNA) markedly enhanced the potency of Rapa to induce growth inhibition. (A) Aktspecific siRNA $(20 \mathrm{nM})$ but not control siRNA $(20 \mathrm{nM})$ reduced Akt protein levels. The expression of Akt protein and $\alpha$-tubulin protein was measured after $24 \mathrm{~h}$. Similar results were obtained in two additional experiments. (B) siAkttransfected MCF-7 cells (๑) or control siRNA-transfected MCF-7 cells (O) $\left(0.5 \times 10^{4}\right.$ cells/well in a 24 -well dish) were cultured with Rapa for 4 days. Then, cell numbers were determined by the MTT assay. Values are expressed as mean \pm standard deviation of three determinations.

treatment with ATO and Rapa inhibited cell growth to $28 \%$ of controls (Fig. 6C). We next examined the effects of a potent PI3K inhibitor LY294002 on Rapa-induced phosphorylation of Akt (Ser473) and Rapa-induced growth inhibition of MCF-7 cells. In agreement with previous reports $(28,29)$, LY294002 $(3 \mu \mathrm{M})$ alone significantly inhibited phosphorylation of both Akt (Ser473) and p70S6K (Fig. 7B). However, this concentration of LY294002 showed only a 30\% inhibition of cell growth (Fig. 7B). LY294002 (3 $\mu \mathrm{M})$ also inhibited Rapa-induced phosphorylation of Akt (Ser473) (Fig. 7B) and could enhance Rapa-induced growth inhibition (from 21 to $88 \%$ inhibition) (Fig. 7A). These results suggest that substances that inhibit Rapa-induced phosphorylation of Akt (Ser473) can enhance Rapa-induced growth inhibition of MCF-7 cells.

Akt siRNA-transfected MCF-7 cells are more sensitive to Rapa for growth inhibition. As mentioned above, our results suggest that the marked effects of combined treatment with CN-A and Rapa on the growth of cancer cells is due to, at least in part, the inhibition of Rapa-induced phosphorylation of Akt (Ser473) by $\mathrm{CN}-\mathrm{A}$. To determine the role of Akt protein, we transfected Akt siRNA to MCF-7 cells and prepared Akt-knockdown MCF-7 cells and then examined the potency of Rapa to induce growth inhibition in cells. Akt-specific siRNA $(20 \mathrm{nM})$ reduced Akt protein (60\% inhibition) (Fig. 8A). Although the growth of control siRNA-transfected MCF-7 cells was slightly inhibited by Rapa, the growth of Akt siRNA-transfected MCF-7 cells was inhibited more significantly by Rapa than that of control siRNA-transfected MCF-7 cells (Fig. 8B). These results suggest the importance of the down-regulation of Akt signaling in effective growth inhibition induced by combined treatment with Rapa plus other substances including CN-A.

\section{Discussion}

Activation of the PI3K/Akt/mTOR signaling pathway contributes to the pathogenesis of many tumor types. The anticancer drug Rapa is a known mTOR-inhibitor. However, Rapa and rapalogs are known to induce Akt activation. IGF-I and insulindependent induction of the PI3K/Akt pathway leads to feedback 
inhibition of signaling due to mTOR/S6K-mediated phosphorylation and degradation of IRS-1. Rapa-induced Akt activation has been primarily attributed to the loss of this negative feedback loop. Akt activation may limit the antitumor efficacy of Rapa and rapalogs (2-6). We previously reported that $\mathrm{CN}-\mathrm{A}$, which is a potent differentiation-inducer of leukemia cells, and Rapa, which is also a differentiation-inducer of leukemia cells, synergistically inhibited the proliferation of MCF-7 cells in vitro and cooperatively reduced the growth of MCF-7 cells in vivo $(17,19)$. This combined treatment with $\mathrm{CN}-\mathrm{A}$ and Rapa induced G1 arrest, but not apoptosis, and induced E-cadherin and senescence-associated $\beta$-galactosidase activity in MCF-7 cells (17). The mechanisms of these combined effects are largely still unknown, although our previous COMPARE analysis suggests that $\mathrm{CN}-\mathrm{A}$ has a unique mode of action on cancer cells (30). In this study, we found that CN-A could inhibit Rapa-induced phosphorylation of Akt in MCF-7 cells. These results suggest that the inhibition of Rapa-induced Akt phosphorylation by $\mathrm{CN}$-A correlates with their effective growth inhibition of cancer cells.

The Hsp90 inhibitor 17-AAG is one of the most studied inhibitors of Hsp90. 17-AAG destabilizes multiple tyrosine kinase receptors and other oncoproteins through Hsp90 inhibition, which results in blocking of proliferation and induction of apoptosis (22-24). 17-AAG also was reported to impair Akt stability and activity. For example, 17-AAG downregulated phosphorylation of Akt (Ser473) in osteosarcoma cell lines (HOS and KHOS/NP) (22), in several solid tumor cell lines (RKO colorectal, MCF-7, AGS gastric adenocarcinoma and U2OS osteosarcoma) (23), and in ovarian cancer cell lines (SKOV3, OVCAR429 and ES2) (24). We found that 17-AAG could inhibit Rapa-induced phosphorylation of Akt (Ser473) and could also significantly enhance Rapa-induced suppression of cell growth in MCF-7 cells (Fig. 6A and B). ATO is an effective treatment for patients with acute promyelocytic leukemia (APL) $(31,32)$. ATO induces differentiation at lower concentrations and induces apoptosis at higher concentrations in APL cells. However, ATO has been less successful in other malignancies at tolerable doses. The doses of ATO required to exert detectable anticancer effects in solid tumors are much higher than those required to inhibit hematological malignancies (33). Therefore, new strategies to enhance the efficacy of ATO, while reducing the dose of ATO in order to avoid severe side-effects, are essential. Previous reports showed that ATO decreased not only Akt activity but also total Akt protein and that the sensitivity to ATO correlated with the degree of Akt protein reductions in leukemia cells, prostate cancer cells, and ovarian cancer cells (25-27). In this study, we found that ATO at lower doses could inhibit Rapa-induced phosphorylation of Akt (Ser473) in MCF-7 cells, and that ATO and Rapa synergistically inhibited the proliferation of MCF-7 cells (Fig. 6C and D). These results suggest that $\mathrm{CN}-\mathrm{A}$ as well as 17-AAG or ATO is possibly a suitable candidate for combination therapy with Rapa to inhibit solid tumor cells. Recently, Loehberg el al (34) reported that anti-malarial chloroquine could prevent rapalog RAD001-induced Akt activation and enhance RAD001-induced inhibition of cell proliferation in luminal MCF-7 cells. However, this combined treatment was not effective in mesenchymal MDA-MB231 breast cancer cells (34). We previously reported that combined treatment with Rapa and CN-A was also effective in inhibiting the growth of MDA-MB231 cells (17). As with recent reports $(28,29)$, the potent well-known PI3K inhibitor LY294002 inhibited Rapa-induced phosphorylation of Akt (Ser473) (Fig. 7B) and was able to enhance the Rapa-induced growth inhibition of MCF-7 cells in our culture conditions (Fig. 7A). Moreover, the growth of Akt siRNA-transfected MCF-7 cells was inhibited more significantly by Rapa than that of control siRNA-transfected MCF-7 cells by Rapa (Fig. 8B). These results suggest the importance of downregulating Akt signaling for the effective growth inhibition induced by combined treatment with Rapa plus CN-A or Rapa plus other substances.

Cyclin $\mathrm{G} 2$ belongs to the ' $\mathrm{G}$ ' family of unconventional cyclins (35). Unlike other cyclins that function to promote cell cycle progression, cyclin $\mathrm{G} 2$ inhibits the cell cycle. It is expressed at modest levels in proliferating cells, peaking during the late S/early G2-phase, and is significantly upregulated as cells exit the cell cycle in response to DNA damage and receptormediated negative signaling $(36,37)$. We previously found that $\mathrm{CN}-\mathrm{A}$ and Rapa rapidly and markedly induced cyclin G2 gene expression in several cancer cells including MCF-7 cells (19). Furthermore, we reported that ectopically inducible cyclin G2 expression potently inhibited the proliferation of MCF-7 cells and that cyclin G2 knockdown induced by cyclin G2 small interfering RNA markedly reduced the potency of $\mathrm{CN}-\mathrm{A}$ plus Rapa to induce growth inhibition (19). These results suggest that CN-A plus Rapa induce inhibition of cancer cell growth through, at least in part, the induction of cyclin G2. FoxO3a is a member of the Forkhead box class $\mathrm{O}$ (FoxO) transcription factor family. FoxO transcription factors regulate diverse cell functions through the regulation of genes involved in cell proliferation and apoptosis (38). In particular, FoxO3a has been reported to activate genes that induce cell cycle arrest, such as p27, p21, p15 and p19, and to suppress the expression of cyclin D2 (38-40). Recently, Fu and Peng (41) reported that several putative FoxO3abinding sites were present in the human cyclin $\mathrm{G} 2$ promoter and overexpression of FoxO3a enhanced the cyclin $\mathrm{G} 2$ promoter activity. Since the activity of FoxO3a is mainly regulated at the level of posttranslational modifications such as phosphorylation and degradation, activation of the PI3K/Akt signaling pathway in response to growth stimuli leads to FoxO3a phosphorylation and subsequent nucleus exclusion (41). In this study, we showed that CN-A suppressed Rapa-induced phosphorylation of Akt (Ser473). It is possible that inhibition of Rapa-induced phosphorylation of Akt (Ser473) by $\mathrm{CN}-\mathrm{A}$ may induce the accumulation of FoxO3a in the nucleus and activate FoxO3a. Therefore, it will be interesting to examine whether CN-A plus Rapa induce inhibition of cancer cell growth through FoxO3amediated induction of cyclin G2.

Meric-Bernstam et al (42) reported that cell lines that are Rapa-sensitive are more likely to have PIK3CA and/or PTEN mutations or basal Akt phosphorylation, and that Rapa leads to a greater increase in Akt phosphorylation in Rapa-sensitive cells. They suggested that feedback loop activation is an indicator of the Rapa response. Montero et al (43) showed that mTORC1 and mTORC2 were constitutively active in ovarian cancer cell lines. Knockdown of raptor or rictor, proteins required for the functioning of $\mathrm{mTORC} 1$ or $\mathrm{mTORC} 2$, respectively, resulted in profound inhibition of ovarian cancer cell proliferation. mTORC2 mainly phosphorylates Akt (Ser473) as PDK2. They found that the knockdown of raptor had a more 
important inhibitory effect than the knockdown of rictor, indicating mTORC1 had a predominant role over mTORC 2 in the control of ovarian cancer cell proliferation (43). These reports suggest that Rapa-induced feedback loop activation of Akt is mainly an indicator of the response to Rapa-induced inhibition of mTORC1-mediated cell proliferation, since mTORC1 has a predominant role over mTORC2 in controlling the proliferation of tumor cells. Another study (44) demonstrated that mTOR inhibition by the rapalog RAD001 was strongly associated with the development of drug resistance due to sustained Akt activation in lung cancer cell lines, and co-targeting mTOR and PI3K/Akt signaling with separate drugs resulted in blocking Akt phosphorylation and enhanced antitumor effects. Therefore, since this Akt activation may limit the antitumor efficacy of Rapa and rapalogs, approaches to prevent Akt activation are important for more efficient growth inhibition of Rapa sensitive tumor cells. We previously reported that treatment with $\mathrm{CN}-\mathrm{A}$ plus Rapa effectively inhibited the proliferation of MCF-7 cells in vitro and in vivo (17). In this study, we found that $\mathrm{CN}-\mathrm{A}$ inhibited Rapa-induced phosphorylation of Akt (Ser473). Our results suggest that the inhibition of Rapa-induced Akt phosphorylation by $\mathrm{CN}-\mathrm{A}$ correlates with their effective growth inhibition of cancer cells. It is also clear that our present and previous studies $(17,19,30,45)$ highly support the ability of $\mathrm{CN}$-A to inhibit tumor growth especially in concert with other drugs. These studies provided evidence that $\mathrm{CN}-\mathrm{A}$ represents a potent chemosensitizer in conjunction with a broad spectrum of drugs including Rapa.

Taken together, our data support the hypothesis that CN-A exerts at least part of its anticancer effects through the modification of the PI3K/Akt/mTOR pathway and suggest that $\mathrm{CN}-\mathrm{A}$ is a promising combination partner of the mTOR inhibitor Rapa or rapalogs.

\section{Acknowledgements}

This study was supported partly by a grant from the Ministry of Education, Culture, Sports, Science and Technology of Japan and Kawano Masanori Memorial Foundation for Promotion of Pediatrics.

\section{References}

1. Jemar A, Bray F, Center MM, Ferlay J, Ward E and Forman D: Global cancer statistics. CA Cancer J Clin 61: 69-90, 2011.

2. Hurvitz SA, Hu Y, O'Brien N and Finn RS: Current approaches and future directions in the treatment of HER2-positive breast cancer. Cancer Treat Rev: May 31, 2012 (Epub ahead of print). doi: 10.10.16/j.ctrv.2012.04.008.

3. Meric-Bernstam FM and Gonzalez-Angulo M: Targeting the mTOR signaling network for cancer therapy. J Clin Oncol 27: 2278-2287, 2009.

4. Engelman JA: Targeting PI3K signaling in cancer: opportunities, challenges and limitations. Nat Rev Cancer 9: 550-562, 2009.

5. Wong KK, Engelman JA and Cantley LC: Targeting the PI3K signaling pathway in cancer. Curr Opin Genet Dev 20: 87-90, 2009.

6. Ma XM and Blenis J: Molecular mechanisms of mTOR-mediated translational control. Nat Rev Mol Cell Biol 10: 307-318, 2009.

7. Yang S, Xiao X, Meng X and Leslie K: A mechanism for synergy with mTOR and PI3 kinase inhibitors. PLoS One 6: e26343, 2011.

8. Wang $X$ and Sun SY: Enhancing mTOR-targeted cancer therapy. Expert Opin Ther Targets 13: 1193-1203, 2009.
9. Hsieh AC, Costa M, Zollo O, et al: Genetic dissection of the oncogenic mTOR pathway reveals druggable addiction to translational control via 4EBP-eIF4E. Cancer Cell 17: 249-261, 2010.

10. Janes MR, Limon JJ, Chen J, et al: Effective and selective targeting of leukemia cells using a TOR1/2 kinase inhibitor. Nat Med 16: 205-213, 2010.

11. Sassa T, Tojyo T and Munakata K: Isolation of a new plant growth substance with cytokinin-like activity. Nature 227: 379, 1970.

12. Asahi K, Honma Y and Hazeki K: Cotylenin A, a plant-growth regulator, induces the differentiation in murine and human myeloid leukemia cells. Biochem Biophys Res Commun 238: 758-763, 1997.

13. Yamamoto-Yamaguchi Y, Yamada K, Ishii Y, Asahi KI, Tomoyasu S and Honma Y: Induction of the monocytic differentiation of myeloid leukemia cells by cotylenin A, a plant growth regulator. Br J Haematol 112: 697-705, 2001.

14. Yamada K, Honma Y, Asahi KI, Sassa T, Hino KI and Tomoyasu S: Differentiation of human acute myeloid leukemia cells in primary culture in response to cotylenin A, a plant growth regulator. Br J Haematol 114: 814-821, 2001.

15. Honma Y: Cotylenin A - a plant growth regulator as a differentiation-inducing agent against myeloid leukemia. Leuk Lymphoma 43: 1169-1178, 2002

16. Yamamoto-Yamaguchi Y, Okabe-Kado J, Kasukabe T and Honma Y: Induction of differentiation of human myeloid leukemia cells by immunosuppressant macrolides (rapamycin and FK506) and calcium/calmodulin-dependent kinase inhibitors. Exp Hematol 29: 582-588, 2001.

17. Kasukabe T, Okabe-Kado J, Kato N, Sassa T and Honma Y: Effects of combined treatment with rapamycin and cotylenin A, a novel differentiation-inducing agent, on human breast carcinoma MCF-7 cells and xenografts. Breast Cancer Res 7: R1097-R1110, 2005.

18. Kawakami K, Hattori M, Inoue T, et al: A novel fusicoccin derivative preferentially targets hypoxic tumor cells and inhibits tumor growth in xenografts. Anticancer Agents Med Chem 12: 791-800, 2012

19. Kasukabe T, Okabe-Kado J and Honma Y: Cotylenin A, a new differentiation inducer, and rapamycin cooperatively inhibit growth of cancer cells through induction of cyclin G2. Cancer Sci 99: 1693-1698, 2008.

20. Sun SH, Rosenberg LM, Wang X, et al: Activation of AKT and eIF4E survival pathways by rapamycin-mediated mammalian target of rapamycin inhibition. Cancer Res 65: 7052-7058, 2005.

21. Wang X, Harkavy N, Shen N, Grohar P and Helman LJ: Rapamycin induces feedback activation of Akt signaling through an IGF-1R-dependent mechanism. Oncogene 26: 1932-1940, 2007.

22. Gazitt T, Kolaparthi V, Moncada K, Thomas C and Freeman J: Targeted therapy of human osteosarcoma with 17AAG or rapamycin: characterization of induced apoptosis and inhibition of mTOR and Akt/MAPK/Wnt pathways. Int J Oncol 34: 551-561, 2009.

23. Vaseva AV, Yallowitz AR, Marchenko ND, Xu S and Moll UM: Blockade of Hsp90 by 17AAG antagonizes MDMX and synergizes with Nutlin to induce p53-mediated apoptosis in solid tumors. Cell Death Disease 2: e156, 2011.

24. Jiao Y, Ou W, Meng F, Zhou H and Wang A: Targeting HSP90 in ovarian cancers with multiple receptor tyrosine kinase coactivation. Mol Cancer 10: 125, 2011.

25. Mann KK, Colombo M and Miller WH Jr: Arsenic trioxide decreases AKT protein in a caspase-dependent manner. Mol Cancer Ther 7: 1680-1687, 2008.

26. Yuan Z, Wang F, Zhao Z, et al: BIM-mediated AKT phosphorylation is a key modulator of arsenic trioxide-induced apoptosis is cisplatin-sensitive and - resistant ovarian cancer cells. PLoS One 6: e20586, 2011.

27. Chiu HW, Chen YA, Ho SY and Wang YJ: Arsenic trioxide enhances the radiation sensitivity of androgen-dependent and -independent human prostate cancer cells. PLoS One 7: e31579, 2012.

28. Ray S, Fry MJ and Darbre PD: Enhanced sensitivity to rapamycin following long-term oestrogen deprivation in MCF-7, T-47-D and ZR-75-1 human breast cancer cells. J Endocrinol 208: 21-29, 2011

29. Elfiky A, Aziz SA, Conrad PJ, et al: Characterization and targeting of phosphatidylinositol-3 kinase (PI3K) and mammalian target of rapamycin (mTOR) in renal cell cancer. J Trans Med 9: 133, 2011 
30. Honma Y, Kasukabe T, Yamori T, Kato N and Sassa T: Antitumor effect of cotylenin A plus interferon-alpha: possible therapeutic agents against ovary carcinoma. Gynecol Oncol 99: 680-688, 2005.

31. Shen Y, Shen ZX, Chen YJ, et al: Studies on the clinical efficacy and pharmacokinetics of low-dose arsenic trioxide in the treatment of relapsed acute promyelocytic leukemia: a comparison with conventional dosage. Leukemia 15: 735-741, 2001.

32. Douer D and Tallman MS: Arsenic trioxide: new clinical experience with an old medication in hematologic malignancies. J Clin Oncol 23: 2395-2410, 2005.

33. Kim KB, Bedikian AY, Camacho LH, Papadopoulos NE and McCullough C: A phase II trial of arsenic trioxide in patients with metastatic melanoma. Cancer 104: 1687-1692, 2005.

34. Loehberg CR, Strissel PL, Dittrich R, et al: Akt and p53 are potential mediators of reduced mammary tumor growth by Chloroquine and the mTOR inhibitor RAD001. Biochem Pharmacol 83: 480-488, 2012.

35. Horne MC, Goolsby GL, Donaldson KL, Tran D, Neubauer M and Wahl AF: Cyclin G1 and cyclin G2 comprise a new family of cyclins with contrasting tissue-specific and cell cycleregulated expressions. J Biol Chem 271: 6050-6061, 1996.

36. Horne MC, Donaldson KL, Goolsby GL, et al: Cyclin G2 is up-regulated during growth inhibition and $\mathrm{B}$ cell antigen receptor-mediated cell cycle arrest. J Biol Chem 272 : 12650-12661, 1997.

37. Bates S, Rowan S and Vousden KH: Characterization of human cyclin G1 and G2: DNA damage inducible genes. Oncogene 13: 1103-1109, 1996.
38. Fei M, Zhao Y, Wang Y, et al: Low expression of Foxo3a is associated with poor prognosis in ovarian cancer patients. Cancer Invest 27: 52-59, 2009.

39. Weidinger C, Krause K, Klagge A, Karger S and Fuhrer D: Forkhead box-O transcription factor: critical conductors of cancer's fate. Endocr Relat Cancer 15: 917-929, 2008.

40. Katayama K, Nakamura A, Sugimoto Y, Tsuruo T and Fujita N: FOXO transcription factor-dependent p15(INK4b) and p19(INK4d) expression. Oncogene 27: 1677-1686, 2008.

41. Fu G and Peng C: Nodal enhances the activity of FoxO3a and its synergistic interaction with Smad to regulate cyclin G2 transcription in ovarian cancer cells. Oncogene 30: 3953-3966, 2011.

42. Meric-Bernstam F, Akcakanat A and Chen H: PI3CA/PTEN mutations and Akt activation as markers of sensitivity to allosteric mTOR inhibitors. Clin Cancer Res 18: 1777-1789, 2012.

43. Montero JC, Chen X, Ocana A and Pandiella A: Predominance of mTORC1 over mTORC2 in the regulation of proliferation of ovarian cancer cells: therapeutic implications. Mol Cancer Ther 11: 1342-1352, 2012.

44. Xu CX, Li Y, Yue P, et al: The combination of RAD001 and NVP-BEZ235 exerts synergistic anticancer activity against non-small cell lung cancer in vitro and in vivo. PLoS One 6: e220899, 2011.

45. Honma Y, Ishii Y, Yamamoto-Yamaguchi Y, Sassa T and Asahi K: Cotylenin A, a differentiation-inducing agent, and IFN-alpha cooperatively induce apoptosis and have an antitumor effect on human non-small lung carcinoma cells in nude mice. Cancer Res 63: 3659-3666, 2003. 